\title{
The Metaphorical Cognitive Mechanism of Spatial Dimensional Term "High"
}

\author{
Jinying Li \\ School of Foreign Languages \\ Shijiazhuang University of Economics \\ Shijiazhuang, P.R. China \\ cathylbd@sina.com
}

\begin{abstract}
The paper, based on the usage of "high", makes a systematic analysis on the English word, a word for spatial dimension. In cognitive field, the linguistic research on metaphor reveals that space is the most basic concept in human cognition, and that it is extremely significant in the process of perception of the world. Spatial concepts are the results of human direct physical experiences. In cognition, space is stored as a schema to be the basis in the cognition of the environment and other domain. On the basis of spatial schema, human beings have constructed the concepts of other fields. It is discovered that the word "high" is so powerful and vivid in the construction of concepts that many abstract ideas have been easily perceived through "high", such as, time, human qualities and morality, degree, mood and attitude, and amount, etc, which can form the cognitive structure and knowledge structure so that it is much efficient for human beings to perceive the nature.
\end{abstract}

Keywords-high; schema; cognition; metaphor; space; construct

\section{INTRODUCTION}

In cognitive linguistics, the development and research on metaphor find that one of the basic concepts of human being, space, plays an important role for exploring the world, and has a significant effect on the formation of concept and cognitive structure. The research on metaphor discloses that human beings have constructed many concepts in other domains with the prototype schema of spatial concepts to understand the characteristics and nature of other domains.

Schema is a cognitive mode. Immanuel Kant, the German philosopher, thought that schema is a specific form or rule of the primary imagination, which is helpful for people to experience and perceive the knowledge and experiences. Bartlett, a British experimental psychologist, maintained that schema can reflect the past and actively organize the past experiences, and that it is a way for human beings to perceive the world. Modern psychologists define schema as the cognitive structure of the knowledge on the things, humanity and surroundings, including the knowledge of the object characteristics and the relationships of the features. Schema is the abstract concept of the whole, and it focuses on the similarities. It helps to deal with new information. One of the important features of schema is that it can represent all the abstract knowledge. In cognition, the past knowledge and experiences are summarized and stored in the mind, then in turn, the stored schema will consciously or unconsciously be awakened and applied when the new information needs processing for comparing, summarizing, and deducing the similarities between the stored schema and the new things so that the new things can be defined and perceived.

\section{THE METAPHORIC USAGE OF "HIGH"}

The studies of modern linguistics indicate that space is one of the categories perceived early by human being in the process of cognizing the universe. The similarities between space and other things are discovered in the cognition of other things. Therefore, the spatial words are metaphorically borrowed, which brings about the spatial metaphors, and broadens and deepens the cognition realm. Lakoff and Johnson, two linguists, thought that spatial metaphors originate in the direct physical experiences. By observing the position and movement relationships of oneself and the surroundings, people can define the concrete and abstract concepts of the surroundings. Zielinsky thought that all the abstract concepts are derived from the concrete spatial metaphors.

"High" in English refers to spatial dimension, a spatial distance. It is used to measure a long distance from the bottom to the top, which is the basic schema of the word. In life, it is metaphorically applied to other domain to construct the concepts and categories.

\section{A. Temporal Domain}

Samuel Alexander holds that space in nature is time, and vice verse. As for human thinking, spatial concepts and temporal concepts are closely related to each other. In cognizing time domain, human beings apply the basic schema of spatial concepts to time, because those concepts can provide the information of the things staying in time. "High", the spatial schema, is used to refer to time, indicating "the middle of a period", "fully developed, or most creative or culminating stage or period".

High noon; high season; high summer

Other examples:

From Florence the early Renaissance style spread through Italy. Donato Bramante's move to Rome ushered in the High Renaissance.

In the sentence, "High Renaissance" was the period in history denoting the apogee of the visual arts in the Italian Renaissance, from the 1490's to 1520's. 
This meaning of "high" may come from the judgment on the position of the sun. When the sun is in the highest position, it is in the middle of the day.

\section{B. The Domains of Qualities or Morality}

The qualities or morality of people vary. In evaluating it, the knowledge and experience of the basic schema of "high", that is, the long distance from bottom to top, is projected on the concepts of qualities, which reflects the differences in quality or morality. Thus, the quality or morality which is praised and respected is good and admired.

Those who have high ideals are always admired by a nation.

A woman of high principle; high-minded (or: high-mindedness); a high character

In all of the phrases or sentences, "high" is metaphorically used for good quality or morality.

\section{The Domain of Hierarchy}

Difference generally exists in human society and nature. However, it is very abstract. In order to express the abstract concept, the spatial schema is borrowed to map the concept of hierarchy. And "high" is related to something good. Actually, "high" not only can map human itself and human life, it can also metaphorically be applied to other creatures and something lifeless.

In a society, there definitely exist the differences of position and status, and the differences are reflected on hierarchy. In the cognition of human being, the degree of position and status means difference in power. Although it is believed in western countries that human being are created equal, it is only a great expectation.

a high official; a man of high standing; high society; a high-ranking official; high life; high and mighty; a high-born boy; high commission; high commissioner; high-up

The word "high" in all the above phrases refers to "near the top in rank or status".

More interestingly, "highness" is used as an address form for the royal family, which indicates that "high" is closely relevant to the top social position or status in cognition.

Besides, the animal and plant realms are distinguished into different ranks. Darwin's theory of evolution suggests that the creatures are developing from lower forms to higher forms, and the higher animals, compared with lower animals, are more complicated in structure, and stronger in life. This point is illustrated by such expressions in English as "higher animals", "higher plants" etc.

Besides, something lifeless can also be related to ranks. "High" means good quality, top quality, near the top in quality or degree, advanced or complex.

High court; higher education; high school; high-grade petrol; high-class restaurant; high quality; etc.

\section{The domains of mood or attitude}

Distinguishing from other animals, human beings have different moods or attitudes which vary according to different situations.

People can be happy or sad. When they are happy, they are in good passion, they are excited, delighted, and even enthusiastic. The schema of the spatial dimensional word "high" can vividly reflect such a mood.

Be in high spirits.

Passions ran high as the election approached.

She is such a highly- strung woman actor.

In addition, the meaning of "high", when used as a noun is an emotion or mood of great excitement or happiness.

They're bound to be on a high after such an incredible victory.

The novel describes the emotional highs and lows of a new romance.

Exercise gives you a high.

And what's more, when someone takes drink or drugs, they are affected, and will have a feeling of extreme pleasure and excitement, which is "high".

The high lasted all night.

He was too high on drugs and alcohol to remember them.

Research findings show that when talking about positive moods and emotions, human beings often use spatial metaphors. A happy person is on the top of world. Some studies indicate that human beings not only use the spatial metaphors to talk about moods and emotional states, but also use the spatial concepts to think about the different moods or emotions.

"High", a spatial dimensional word, can not only be used to construct the concept of "mood", but the abstract concept of "attitude", which is very easy for human being to reason and compare the two different categories of concepts, and it is very helpful in understanding the meaning.

High-hat; high manner

She is/gets on her high horse.

Such an image is vividly created by "high": when one is proud or arrogant, he will lift his head as if he is flying into the sky, far away from the earth.

When people have positive attitude toward something, it is natural for them to see the bright side, and make good evaluation. From this perspective, the positive and good evaluation is resulted from people's favorable attitudes.

You seem to have a high opinion of yourself.

She is held in very high regard by her colleagues.

As an organizer, she earned high praise from his boss.

We had high hopes for the business.

\section{E. The Domain of Volume}

In life and work, human beings can't do without the volume or quantity. Human experiences tell such fact that the size of the quantity or volume is directly connected with the spatial dimension. The more things are packed up, the further distance it is from the ground, which is exactly the feature that "high" invents in human mind. The metaphorical concept constructed by "high" is very powerful. It can refer to greater than normal in quantity, a large amount of ingredient, large density, or more expense, etc. In the following part, some of the respects concerning human life will be illustrated.

1) Voice close to the top range of notes

High pitch; in a high voice; high-keyed

I can't reach the high notes.

I can't sing that high. 
In the above examples, "high" refers to the sound or voice which is close to the top of a particular range of notes, an acute pitch, a high frequency.

2) A lot of substance

High proof; a food high in vitamin; a high-fat diet; a high potassium content; high analysis; have a high color, etc

"High" in the above phrases means containing a lot of substance or quality, high density.

3) A large amount

High interest rate; highly paid job; high price; etc

The cost in terms of human life was high.

A high proportion/ percentage of our staff are female.

If you want better public services, you'll have to pay higher taxes. It is as simple as that.

Temperatures remained high for the rest of the week.

Lower-paid workers often can't afford the high cost of living in the capital.

"High" in the above phrases or sentences refers to a large amount of rate, cost, or price, etc.

\section{F. The Domain of Degree}

Degree indicates the extent to which something happens or is the case, or the amount which something is felt. A large degree means the large extent or distance from the surface to the point mentioned. And large distance is exactly what the word "high" basically means. Thus the spatial schema of "high" can project the concept of degree, because the features that "high" can indicate are distinguishing, extraordinary, and thus, easily attract attention.

High treason; a high insult; a high crime; high-test; high level of pollution; a high risk of injury

"High" in the above phrases denotes serious extent, dangerous situations; therefore, it should be give a weight.

The government made decisive policy at this high hour of the country's history. "High" refers to a very important and influential moment which can determine the country's historical development.

High definition; high fidelity; high beam; high dependency; high precision; high pressure; a financial high-wire act, a high explosive, etc.

Monkeys are highly social animals.

"High" in the above examples indicates large degree, powerful, or large extent.

\section{G. Other Domains}

Except the concepts mentioned above, the schema of "high" is also very beneficial in the cognition of other things. It helps to form and construct the concepts.

Some game-birds are kept until they are high before cooking. Here "high" denotes that the meat is beginning to go bad.

A high Tory (a person who holds traditional Conservative opinions)

High-sounding (one's language is pretentious, high-flown); high road (main road); high wire (a length of rope or wire stretched tight high above the ground and used for balancing acts).

\section{CONCLUSION}

Cognitive linguists think that metaphors can help to facilitate the cognition of a conceptual system. According to Lakoff and Johnson, the human conceptual system is structured around only a small set of experiential concepts concepts that emerge directly out of experience and are defined in their own terms. The nature is in the constant change. The world requires continuously understanding. However, in the process of cognition, human beings don't always create new concepts to describe either the concrete or abstract things, which is not necessitated, and doesn't observe the "economy" principle in concept formation. Instead, they will analyze, and summarize the characteristics of the things to be conceived, and study their abstract features or qualities. Then they will search in mind the features of existing schema, and make comparison or contrast with the things known to them, so that they can find something in common between the cognized thing and the new things under study, whereby the new concepts and categories are constructed with the knowledge or information stored in mind. Space is one of the forms for the substance to exist, and one of the important factors for human beings. Human activity is the movement in space. The cognition on spatial locality is the basis for human beings to perceive the world. After human beings have first cognized space, they begin to understand other concepts with the schema of space. The spatial metaphors offer the insights into the conceptual system, and serve as the schema basis to structure the new concepts. "High", as a spatial dimensional word, has a very powerful metaphorical function. The constructed concepts in other domains, projected by the spatial schema of "high", have played a great role in human cognition and interpretation of nature.

\section{REFERENCES}

[1] C. Clive. Metaphor and Continental Philosophy: From Kant to Derria New York: Routledge. 2007.

[2] F.C. Bartlett. Remembering: A Study in Experimental and Social Psychology. Cambridge, England: Cambridge University Press. 1932.

[3] G.Lakoff, \& M. Johnson. Metaphors We Live By. Chicago: University of Chicago Press. 1980.

[4] J. M. Mandler. Stories, scripts, and scenes: Aspects of schema theory. Hillsdale, NJ: Lawrence Erlbaum Associates. 1984.

[5] P. Ricoeur. The Rule of Metaphor: Multi-disciplinary Studies of the Creation of Meaning in Language. London: Routledge \& Kegan Paul. 1986.

[6] B. Armbruster. "Schema Theory and the design of content-area textbooks". Educational Psychologist. vol 21. 1996, pp253-276

[7] H. Xu. "A Review of Domestic Studies on Noun of Locality from Spatial Metaphor Perspective". Journal of Hebei North University (Social Science Edition). vol.27. 2011, pp42-44.

[8] L. J. Old. "Utilizing Spatial Information Systems for Non-Spatial-Data Analysis”. Scientometrics, vol. 51.2001, pp563-571.

[9] R. Cavell. "McLuhan and Spatial Communication. Western Journal of Communication. vol 63. 1999, pp348-363.

[10] W.P. Dai, \& W.B. Pei. "On Metaphor of Vertical Locality Words 'Up' and 'Down'in Chinese and English'. Journal of Sichuan University of Science \& Engineering (Social Science Edition). vol.21 2006, pp91-94. 
[11] Y.J. Ren.. "The Cognitive Semantic Analysis on Spatial Dimensional Words 'High'and 'Low' ". Journal of Liaocheng Teachers University. vol 2. 2001, pp123-125.
[12] Y. P. Wang, \& D.D. Wang. "A Cognitive Comparative Study on Spatial Dimensional Term'High'in English and Chinese". Journal of Jiaxing University. vol. 23. 2011, pp136-139. 